from this diehard attitude, there are several considerations which must be taken into account by the commercial grower. For example, the size of pot into which a plant is potted is very often governed by the space available; this is particularly true in the case of the grower of decorative plants for sale in pots.

The skill of the worker under whose care the plants are placed is a most important factor which cannot be assessed experimentally, but which has a profound influence on the ultimate result. It has frequently been said that the horticultural worker who cannot use the watering can or hosepipe efficiently and intelligently cannot grow a good plant or produce a good crop. There are many similar variable factors in plant production which cannot be standardized except by the most elaborate equipment, but which are controlled to some extent by the human factor. Therefore, however far the fundamental processes of horticulture are standardized the human factor will ultimately decide the quality of the plant.

Mr. Lawrence has, in the experiments described, blasted tradition; he has opened up new lines of approach to many problems; but it is very necessary that the experimental results shall be linked with the economics of plant production, and further experiments on these lines are necessary.

In the last part of his book Mr. Lawrence has explored new ground and has collected together a vast amount of data on the natural illumination of glasshouses. The information given is of great value and has already influenced the design of glasshouses. The importance of light in the production of winter crops is emphasized and suggestions are made for obtaining improved winter illumination. It is diffi. cult to understand why work has not been done previously on this and many other problems concerning glasshouse construction.

This is a book which is stimulating and, in many ways, provoking. It should be read by all who are interested in the production of glasshouse crops, for in it they will find considerable food for thought.

Mr. Lawrence is to be congratulated on the production of this book, which is a contribution to the fundamental knowledge of glasshouse crop production of very real value.

WILFRED CORBETT

\section{TECHNOLOGICAL RESEARCH IN SWITZERLAND}

Industrial Research in Switzerland

Its Institutional and Economic Background. By Prof. Ronald S. Edwards, in collaboration with Charles La Roche. Pp. ix + 111. (London : Sir Isaac Pitman and Sons, Ltd., 1950.) 21s. net.

P ROF. R. S. EDWARDS has followed his earlier study of the economic aspects of the research associations in Great Britain with a study, in collaboration with Dr. C. La Roche, of the Federal Institute of Technology, Zurich, of the organization of industrial research and development in Switzer. land. The book is based on a survey of Swiss industrial research institutions, together with discussions with firms, research institutions, universities and government departments, and includes some information not elsewhere available. There is a select bibliography, prepared by Dr. C. La Roche, and much useful information is collected in the appendixes, dealing with research foundations, the scientific societies and the government research institutes.

The book appears to be designed as a contribution to current discussions on the increases of industrial productivity. It first briefly outlines the industrial pattern of Switzerland and the extent to which research is fostered in industry. This is followed by a chapter on the universities and industry, in which some comparison is made between Swiss and British universities, and the relations between industry and the universities in Switzerland are discussed. A chapter on institutions for co-operative industrial research makes good a gap; the remaining chapters deal with the Federal Government as a sponsor of research, and with research, taxation and the patent system, and finally Prof. Edwards attempts to outline the genera! influences in Swiss life that must be taken into account in seeking the root causes of Swiss industrial achievement.

One merit of this book is that, although it makes many suggestive comments on the differences between the pattern and practice of industrial research in Great Britain and in Switzerland, Prof. Edwards never attempts to push the comparison too far. He is fully aware of the differences in definition, for example, which may make comparison between one industry or one country and another misleading, even where figures exist as a basis. The chapter on the universities and industry may well prove to be the one of most general interest, and its account of science and technology in the universities has a bearing on discussions on higher technological education in Britain. It appears from the analysis presented here that, out of its relatively larger university population as compared with that of Great Britain, Switzerland has a higher proportion of students reading applied science and technology, and that the difference has become more marked since the Second World War. On the other hand, Great Britain spends more per student and the ratio of staff to student has increased slightly, whereas in Switzerland it has decreased appreciably since before the War.

Prof. Edwards's comparison between Switzerland and Great Britain is not unflattering to the latter; but it does not encourage complacency. He points to some weaknesses in the Swiss system, particularly in regard to fundamental research and the lack of openings in academic life. He suggests that a fullscale study of Swiss technical schools, and especially of the Federal Institute of Technology, their organization, administration, curricula and relations with industry, both in regard to training and research, would make a more important contribution to the current debate in certain circles in Britain on the future of technological education than a study of the relations between industry and the universities in the United States now being investigated by a team under the Anglo-American Productivity Council. The great problem, in his view, which Great Britain has not yet fully solved, is how to adapt middle and higher education to meet the needs of the large number of students who must find - and who it is hoped will want to find-their careers in the middle and upper ranks of industry and trade. Prof. Edwards does not claim that his present essay is more than a sketch. Whether or not it stimulates the further inquiry he suggests, it should at least assist in keeping on a factual and practical basis future discussions on productivity and on technological education.

R. BRIGHTMAN 